\title{
A CLASSIFICATION OF THE FUNCTIONAL END-RESULTS OF INJURY TO THE CERVICAL SPINAL CORD
}

\author{
By D. J. E. Cheshire, M.B., B.S., D.Phys.Med. \\ Spinal Injuries Centre, Austin Hospital, Heidelberg, Victoria, Australia
}

EARLY in 1967 Michaelis took an important initiative when he sent a questionnaire to colleagues throughout the world and invited them to think seriously about the terminology they were using in the classification of spinal cord injuries. The subject was taken further at the Society's next Annual Meeting when Michaelis (1967) opened a discussion on the replies to his questionnaire, but this discussion concentrated mainly on nomenclature, and the relative merits and demerits of existing systems.

It is, of course, impossible to do everything at once, and the Society rightly took first things first, but it is felt that, now the Society is coming to grips with diagnostic nomenclature, it is appropriate to move on, and to discuss the present inadequacies in our classifications of the functional end-results of spinal cord injury. One must remember that it is only about 25 years since spinal cord injury became a subject for serious scientific study, and that, before and during this time, most of the literature has come from orthopaedic surgeons and neurosurgeons who have been describing, and disputing, the different types of treatment of the primary lesion. These authors have been mainly 'urgent surgeons' and it is not surprising that the literature is heavily biased towards descriptions of the initial skeletal and neurological presentations, and that the end-results should so often be described in such grossly inadequate terms as 'Excellent', 'Good', 'Fair' and 'Bad'. A grievous effect of this tendency is that readers of the literature have had the greatest difficulty in interpreting the results of other workers and in evaluating the relative merits and demerits of the proposed methods of treatment.

It is intolerable that such a situation shall be permitted to continue any longer. The majority of serious clinicians in our field are today physicians and surgeons who are concerned with the care of the total patient for the duration of his life, and we have continued for too long without clearly defined standards whereby we may evaluate the functional end-results obtained by a specific method of early treatment as practised by a colleague on the other side of the world. The 'operative' versus 'conservative' dispute is still unresolved, but how can it be until we clearly define the end-results of our primary treatment?

Practising in Australia, where there is a very high incidence of injury to the cervical spinal cord, and being in the fortunate, if not unique, position of receiving virtually Ioo per cent. of all cord trauma, and 70 per cent. of it within 24 hours of the accident, the study of acute cervical cord trauma has not unnaturally become a dominant interest.

The first major research task was to create an adequate régime for the respiratory management of the patient with acute traumatic tetraplegia (Cheshire, I964; Cheshire \& Foster, 1964; Cheshire \& Coates, 1966). This was essential as the functional end-results of a particular method of primary treatment are only valid if the early death-rate is reduced to an absolute minimum. To take an extreme example, if an author presents a series of cases of cervical cord trauma treated by a 
particular method, and he has an early mortality rate of 50 per cent., the functional end-results of his surviving 50 per cent. would be statistically worthless.

Because of the peculiar local conditions in Australia, and because the author is proud to have been taught and influenced by Sir Ludwig Guttmann, he has long felt that he could make a worthwhile contribution by analysing a large series of acute cervical cord injuries, all receiving primary treatment in a specialised Spinal Injuries Centre, and all, or very nearly all, treated conservatively by a régime which results in an acute death-rate as low, or lower, than that achieved elsewhere. However, an essential part of such a project is that there must be a classification of functional end-results which is sufficiently clear to permit other physicians to make direct and accurate comparison with their own results. A basic thought behind this project is that unless, and until, there is such a functional classification of end-results there will be no hope of resolving the fundamental disagreement between the 'conservatives' and the 'interventionists'.

To the physician who is concerned with the long-term management and total care of his patients, a classification of the end-results of treatment must be largely a functional classification, and not a classification based on the more academic criteria of detailed and individual motor, sensory or reflex functions. A careful study of the literature has led to the opinion that no adequate classification of the end-results of trauma to the cervical spinal cord presently exists, and that it is necessary to develop such a classification.

The following represents an attempt to fill this gap in our research equipment. Doubtless the proposed classification can be improved, but at least it covers the whole spectrum of possible end-results, and it is submitted that this classification has the merit of incorporating, so far as is possible, the main features of the commonly observed patterns of incomplete tetraplegia, such as the Brown-Sequard syndrome (I86I), the Acute Central Cervical Spinal Cord Syndrome (Schneider et al., I954) and the Acute Anterior Cervical Spinal Cord Syndrome (Schneider, 1955). It is further claimed that this classification, whilst avoiding dependence upon anatomical and physiological minutiae, avoids the other extreme of being a classification too greatly dependent upon the patient's age, intellect or initiative. It is submitted that some classifications, being greatly dependent upon the patient's performance in specific Activities of Daily Living tasks, and through the use of such criteria as 'Independent', 'Partially Independent', and 'Dependent' tend to down-grade the patient with poor intellect or initiative, and cause his end-result to be rated lower than either his method of primary treatment or his neurological residua should warrant. It is felt that such classifications as that proposed by Michaelis (1969), whilst being of the greatest value in demonstrating the functional end-result to non-specialists, paramedical personnel, and lawyers do not have a strong enough neurological basis for the specialist who seeks to analyse the endresults of his primary treatment or to compare his results with those of another specialist using different methods of treatment.

Thus, at some length, is introduced a classification which is complementary to that of Michaelis (I969), but intended for a different purpose.

\section{Complete Recovery}

No abnormal neurological signs, and complete functional recovery. (Seen only in cases of spinal cord concussion.) 


\section{Incomplete Preservation or Recovery}

\section{Group ' $A$ '}

(i) Full power and normal sensation-or only minimal impairment.

(ii) Very slight residual spasticity.

(iii) Total ambulation without aids.

(iv) Normal bladder function.

(v) Can almost always return to previous employment.

\section{Group 'B'}

(i) Significant motor and/or sensory impairment.

(ii) Greater residual spasticity.

(iii) Reasonable function in both hands, though often impairment of higher skills.

(iv) Total ambulation, usually without aids, though weakness, sensory impairment and spasticity may limit endurance, agility, climbing, etc.

(v) Bladder usually normal, though occasionally there may be precipitancy and/or stress incontinence.

(vi) Fully employable in a suitable occupation.

\section{Group ' $C$ '}

(i) Greater motor and sensory loss.

(ii) Moderate spasticity, often asymmetric.

(iii) One good hand, but the other is usually severely impaired.

(iv) Walks satisfactorily, but often requires a caliper on one leg and one crutch or stick.

(v) Normal bladder control is often lost and the male patient usually uses a urinal.

(vi) Should be employable in a suitable occupation.

(This group frequently presents a modified Brown-Sequard syndrome.)

\section{Group ' $D$ '}

(i) Good power in the legs, but spasticity in the legs and/or weakness in the hands (for the use of crutches) usually severely limits ambulation.

(ii) Severe weakness and spasticity in the hands results in poor practical manual function.

(iii) Neurogenic bladder-the male patient wears a urinal.

(iv) Severely restricted opportunities for employment unless the patient is of high intellect.

(This group is frequently the sequel of the Acute Central Cervical Spinal Cord Syndrome.)

\section{Group ' $E$ '}

(i) If there be any motor function below the level of the lesion, it is usually of academic rather than of practical significance.

(ii) Sensory function below the level of the lesion is often confined to the posterior columns.

(iii) Wholly confined to bed and wheelchair (except for therapeutic standing).

(iv) Neurogenic bladder. 
(v) Rarely employable outside the home unless of high intellect. (This group includes the patients with the severe sequelae of the Acute Anterior Cervical Spinal Cord Syndrome.)

\title{
3. No Recovery
}

(i) Complete motor and sensory paralysis below the level of the lesion.

(ii) Wholly confined to bed and wheelchair (except for therapeutic standing).

(iii) Neurogenic bladder.

(iv) Rarely employable outside the home unless of high intellect.

This classification has been developed during the five years since I964. The author's series of acute injuries to the cervical spinal cord presently numbers 257, and it is felt that the classification of a series of this size provides a reasonable test. Having classified the series as a whole and also the separate types of injury to the cervical spine and cord, it is felt that this classification is practical, easy to use, and, most important, is of real value in leading one to a clear vision of the functional end-results of specific lesions.

\section{SUMMARY}

I. The necessity for an adequate classification of the functional end-results of injury to the cervical spinal cord is discussed.

2. Such a classification, covering the complete spectrum from total recovery to total tetraplegia, is presented.

\section{REFERENCES}

BRown-Sequard, E. (I86I). Lectures on the Diagnosis and Treatment of the Principal Forms of Paralysis of Lower Extremities. Philadelphia: Collins.

Cheshire, D. J. E. (1964). Int. F. Paraplegia, I, 252.

Cheshire, D. J. E. \& Foster, K. M. (I964). Int. F. Paraplegia. 2, I4I.

Cheshire, D. J. E. \& Coats, D. (I966). Int. F. Paraplegia, 4, I.

Michaelis, L. S. (I968). Int. F. Paraplegia. 6, 46-and subsequent discussion.

Michaelis, L. S. (I969). Int. F. Paraplegia, 7, I.

SCHNEIDER, R. C. (I955). F. Neurosurg., 12, 95.

SCHNeIder, R. C., Cherry, C. \& PANTEK, H. (I954). F. Neurosurg., II, 546.

\section{THE FRENCH POINT OF VIEW IN THE CLASSIFICATION AND NOMENCLATURE IN PARAPLEGIA}

\author{
Presented by P. Dollfus, M.D. \\ Mulhouse, France
}

IN an attempt to give an idea of the actual neurological classification of spinal cord lesions, in France, a meeting was held by M. MAURY (Fontainebleau), PH. LACERT and S. Pannier (Garches), J. P. Willot (Berck), G. Pelot (Invalides), J. Benassy (Paris) and the reader. This paper was afterwards submitted to all participants.

All French Centres, except one, have adopted a classification of tetraplegia or paraplegia, wanting to remain within the affected area and not below the last intact 